\title{
Patient, client or service user? A survey of patient preferences of dress and address of six mental health professions
}

\section{AIMS AND METHOD}

A positive therapeutic relationship is essential to psychiatry and should take into account patients' preferences. Preferences of 133 community care patients were surveyed regarding dress and forms of address of six professions. Participants' sex, age, ethnicity and diagnosis were recorded.

\section{RESULTS}

Ninety-eight per cent of participants expressed a preference. While most preferred to be called 'patients' by general practitioners ( $75 \%$ ) and psychiatrists $(67 \%)$, there was no statistically significant difference in preference for the term 'patient' or 'client' when used by community psychiatric nurses, occupational therapists, psychologists or social workers. Participants over the age of 40 preferred the term 'client'. Asymmetrical relationships were preferred with general practitioners and psychiatrists, evidenced by a preference to be addressed by first name ( $71 \%$ and $68 \%$, respectively), to address the professional by title $(81 \%$ and $80 \%$, respectively), and the professional to be 'smartly' dressed ( $67 \%$ and $66 \%$, respectively).

\section{CLINICAL IMPLICATIONS}

A more differentiated approach may be suggested by taking professional background and some demographic characteristics into consideration.
A positive therapeutic relationship is a fundamental component of psychiatry (McGuire et al, 2001) and should take into account patients' preferences regarding how they are addressed by mental health professionals. Despite the current popularity of terms such as 'client' and 'service user', evidence indicates that people prefer to be addressed as 'patients'. Indeed, a questionnaire administered to psychiatric out-patients in inner-London revealed that $77 \%$ preferred the term 'patient' to 'client' (Ritchie et al, 2000). A survey assessing preferences regarding psychiatrists' dress and forms of address revealed that: $70 \%$ preferred to be called 'patients' rather than 'clients'; $50 \%$ wished to be called by their first name and $50 \%$ had no preference; and that $95 \%$ preferred to address their doctor by title (Swift et al, 2000). Furthermore, the psychiatrists' attire was related to the participants' ratings of competence, ease in forming a trusting relationship and friendliness (Swift et al, 2000). While these surveys help to clarify preferences of dress and address in psychiatry, they have not examined possible differences according to different professionals. People in mental health services are typically engaged with a range of professionals, including general practitioners (GPs), psychiatrists, community psychiatric nurses, social workers, occupational therapists and psychologists. Preference variations in how they address and are addressed may suggest qualitative differences in terms of expectations of familiarity or authority according to the role of the professional. This study aims to investigate community care patients' preferences of terms of address by, and dress of, six mental health professionals - taking into account their sex, age, ethnic origin and diagnosis.

\begin{abstract}
Method
The patient sample was recruited from the case lists of care coordinators from community mental health centres across East London. Participants were selected on the basis that they have a severe mental illness and are out-patients in the care of a community mental health care team. The study was approved by the East London and City Research Ethics Committee. Four hundred and eighty-one patients were sent a letter explaining the purpose of the study. In alignment with recommendations made by Parkman and Bixby for community interviewing (1996), a follow-up call was made, inviting the patients to participate in an interview at a location that would be convenient for them. One hundred and thirty-three patients agreed to participate, and requested that the interview be held at their home.

Participants were provided with an information sheet on the research project and were asked to complete a written consent form. The survey comprised four questions of preference with regard to six mental health professionals - general practitioners, psychiatrists, community psychiatric nurses, psychologists, occupational therapists and social workers. The participants were asked:

(1) whether they preferred to be addressed as a 'patient', 'client' or 'service user';

(2) whether they preferred to address each professional by their first name or title and last name;

(3) whether they preferred to be addressed by each professional by their first name or title and last name;

(4) whether they preferred to see each professional 'smartly/formally dressed' or 'casually/informally dressed'.
\end{abstract}


The questionnaire layout provided categorical terms of preference, for instance:

original papers

"I would rather be addressed by a general practitioner as: (a) a patient;

(b) a client;

(c) a service user;

(d) no preference".

Participants' sex, age, ethnic origin and diagnosis

(according to DSM-IV (American Psychiatric Association, 1994) classification guidelines) were also recorded. Sixtythree participants were male and 70 were female. Sixtysix were White, 19 were Black Caribbean, 16 were Black African, 5 were Black other, 10 were Pakistani, 2 were Bangladeshi and 10 were of other ethnic origin. While 78 had schizophrenia, delusional or schizoaffective disorder, 46 had mood disorder and nine had another disorder. Seventy-seven of the participants were over the age of 41 and 56 were under the age of 40 . Preference frequencies for each of the four questions were recorded according to each profession and were then crosstabulated with each of the four demographic variables. Pearson's chi-squared was applied to the results to test for statistical significance.

\section{Results}

\section{'Patient', 'client' or 'service user'?}

Of the participants that had a preference of term of address (98\%) a significant proportion reported that they would prefer to be called 'patients' by general practitioners and psychiatrists rather than 'clients' or 'service users'. Slightly more participants said that they would prefer to be called 'patients' by community psychiatric nurses, psychologists and occupational therapists than 'clients', but this difference was not statistically significant. Slightly more people preferred that social workers use the term 'client' than 'patient', but again, this difference was not statistically significant (Table 1).

While more females preferred to be called 'clients' by community psychiatric nurses, psychologists, occupational therapists and social workers rather than 'patients' and more males preferred to be called 'patients' by each of the professions, this difference was not statistically significant. A significant proportion of participants aged 41 and over preferred the term 'patient' to be used by all of the professions in contrast with participants aged 40 and younger, who preferred the term 'client' (Table 2). Furthermore, while White patients appeared to prefer the term 'client' be used by community psychiatric nurses, psychologists, occupational therapists and social workers compared with Caribbean, Indian and Pakistani participants who preferred the term 'patient', this difference was not statistically significant. More people diagnosed with schizophrenia preferred to be called 'patients' by the professional groups compared with people diagnosed with mood disorder, who preferred to be called 'clients'. However, this difference was not statistically significant.
Table 1. Patient, client or service user? Frequencies of participants' preference of terms of address by GPs, psychiatrists, CPNs, psychologists, OTs and social workers

\begin{tabular}{|c|c|c|}
\hline Professional & Term of address & Frequency \\
\hline \multirow[t]{4}{*}{ GP } & Patient & $100(75 \%)^{*}$ \\
\hline & Client & $22(17 \%)^{*}$ \\
\hline & Service user & $9(7 \%)$ \\
\hline & No preference & $2(2 \%)$ \\
\hline \multirow[t]{4}{*}{ Psychiatrist } & Patient & $89(67 \%)^{*}$ \\
\hline & Client & $30(23 \%)^{*}$ \\
\hline & Service user & $12(9 \%)$ \\
\hline & No preference & $2(2 \%)$ \\
\hline \multirow[t]{4}{*}{ CPN } & Patient & $63(47 \%)$ \\
\hline & Client & $57(43 \%)$ \\
\hline & Service user & $11(8 \%)$ \\
\hline & No preference & $2(2 \%)$ \\
\hline \multirow[t]{4}{*}{ Psychologist } & Patient & $62(47 \%)$ \\
\hline & Client & $59(44 \%)$ \\
\hline & Service user & $13(10 \%)$ \\
\hline & No preference & $2(2 \%)$ \\
\hline \multirow[t]{4}{*}{ OT } & Patient & $59(44 \%)$ \\
\hline & Client & $59(44 \%)$ \\
\hline & Service user & $13(10 \%)$ \\
\hline & No preference & $2(2 \%)$ \\
\hline \multirow[t]{4}{*}{ Social worker } & Patient & $55(41 \%)$ \\
\hline & Client & $63(47 \%)$ \\
\hline & Service user & $13(10 \%)$ \\
\hline & No preference & $2(2 \%)$ \\
\hline \multicolumn{3}{|c|}{${ }^{*} P=0.02, \mathrm{df}=1$ (Chi-squared Pearson) } \\
\hline \multicolumn{3}{|c|}{$\mathrm{GP}=$ general practitioner } \\
\hline \multicolumn{3}{|c|}{$\mathrm{CPN}=$ community psychiatric nurse } \\
\hline \multicolumn{3}{|c|}{ OT=occupational therapist } \\
\hline
\end{tabular}

\section{First name or title?}

While most participants preferred to be addressed by their first name, there was a difference in preference according to the participants' address of the different professionals. Most preferred to address GPs and psychiatrists by their title and last name, however, most preferred to address other professionals by their first name (Table 3).

\section{Smartly or casually dressed?}

While most participants preferred to see both GPs and psychiatrists 'formally/smartly dressed', there was no statistically significant preference regarding the other professionals (Table 3).

\section{Discussion}

The present survey supports previous research, which indicates a preference for the term 'patient' to that of 'client' or 'service user'. This preference holds robustly with regard to GPs and psychiatrists, but less so with regard to community psychiatric nurses, psychologists and occupational therapists (with nearly as many preferring the term 'client' to 'patient'). It does not hold at all with regard to social workers (where slightly more prefer 
Table 2. Frequencies of participants' preference of terms of address by GPs, psychiatrists, CPNs, psychologists, OTs and social workers according to age group

\begin{tabular}{|c|c|c|c|}
\hline \multirow[t]{2}{*}{ Professional } & \multirow[t]{2}{*}{ Term of address } & \multicolumn{2}{|l|}{ Age group } \\
\hline & & $<41$ years & $>41$ years \\
\hline \multirow[t]{4}{*}{ GP } & Patient & $54(70 \%)^{* *}$ & $46(82 \%) * *$ \\
\hline & Client & $17(22 \%) * *$ & $5(9 \%)^{* *}$ \\
\hline & Service user & $5(6 \%)$ & $4(7 \%)$ \\
\hline & No preference & $1(1 \%)$ & $1(1 \%)$ \\
\hline \multirow[t]{4}{*}{ Psychiatrist } & Patient & $48(62 \%)^{* *}$ & $43(77 \%)^{* *}$ \\
\hline & Client & $21(27 \%)^{* *}$ & $7(13 \%)^{* *}$ \\
\hline & Service user & $7(9 \%)$ & $5(9 \%)$ \\
\hline & No preference & $1(1 \%)$ & $1(1 \%)$ \\
\hline \multirow[t]{4}{*}{ CPN } & Patient & $30(39 \%)^{*}$ & $33(59 \%)^{*}$ \\
\hline & Client & $40(52 \%)^{\star}$ & $17(30 \%)^{*}$ \\
\hline & Service user & $6(7 \%)$ & $5(9 \%)$ \\
\hline & No preference & $1(1 \%)$ & $1(1 \%)$ \\
\hline \multirow[t]{4}{*}{ Psychologist } & Patient & $31(40 \%)^{*}$ & $33(59 \%)^{*}$ \\
\hline & Client & $41(53 \%)^{*}$ & $16(29 \%)^{*}$ \\
\hline & Service user & $4(5 \%)$ & $6(11 \%)$ \\
\hline & No preference & $1(1 \%)$ & $1(1 \%)$ \\
\hline \multirow[t]{4}{*}{ OT } & Patient & $30(39 \%)^{*}$ & $33(59 \%)^{*}$ \\
\hline & Client & $42(55 \%)^{*}$ & $14(25 \%)^{*}$ \\
\hline & Service user & $4(5 \%)$ & $8(14 \%)$ \\
\hline & No preference & $1(1 \%)$ & $1(1 \%)$ \\
\hline \multirow[t]{4}{*}{ Social worker } & Patient & $27(35 \%)^{*}$ & $33(59 \%)^{*}$ \\
\hline & Client & $44(57 \%)^{*}$ & $19(34 \%)^{*}$ \\
\hline & Service user & $5(6 \%)$ & $2(4 \%)$ \\
\hline & No preference & $1(1 \%)$ & $1(1 \%)$ \\
\hline \multicolumn{4}{|c|}{${ }^{*} \mathrm{P}=0.05, \mathrm{df}=1$ (Chi-squared, Pearson) } \\
\hline \multicolumn{4}{|c|}{${ }^{*} P=0.02, \mathrm{df}=1$ (Chi-squared, Pearson) } \\
\hline \multicolumn{4}{|c|}{$\mathrm{GP}=$ general practitioner } \\
\hline \multicolumn{4}{|c|}{$\mathrm{CPN}=$ community psychiatric nurse } \\
\hline \multicolumn{4}{|c|}{ OT=occupational therapist } \\
\hline
\end{tabular}

the term 'client' to 'patient'). That people prefer to be addressed by GPs, psychiatrists, community psychiatric nurses, occupational therapists and psychologists as 'patients' may reflect their role expectations according to their medical diagnosis, as opposed to social workers, who typically focus on their social role (i.e. accessing services, obtaining benefits and housing). Indeed, a study by Wooff et al (1988), comparing the practice of community psychiatric nurses and mental health social workers in community care, illustrated how distinctly the two professions work. While mental health social workers tend to discuss a wide range of topics and are concerned with patient interactions with family and community networks, community psychiatric nurses focus mainly on psychotic symptoms, treatment changes and medication. Preference of address among these professions cannot be assumed, however, as it appears that the sex, age, ethnicity and diagnosis of participants might result in some differences. Indeed, more participants who are women, under the age of 40 , White and with a diagnosis of mood-disorder appear to prefer the term 'client' to 'patient'. By contrast, more participants who are men, over the age of 40, of Black Caribbean, Indian or Pakistani ethnic origin and with a diagnosis of schizophrenia appear to prefer the term 'patient'. It may be suggested that the term 'patient' is in alignment with a more traditional paternalistic relationship - one that emphasises the authority of the professional and the relative passivity of the patient. Conversely, the term 'client' reflects a more consumer or collaborative type of relationship - characterised by a more non-hierarchical form of interaction. Some similar and other demographic variables have been found to predict a preference for a 'paternalistic' type of relationship in general medicine, including a greater severity of illness, older age, lower income, lower education, African ethnicity and male sex (Geller et al, 1976; Benbassat et al, 1998; Shelton, 1998; Coulter, 1999; Cooper-Patrick et al, 1999). A more 'flexible' approach in addressing patients may be suggested by taking professional background and certain demographic variables into account.

An asymmetrical or authoritative form of address appears to be preferred with GPs and psychiatrists (evidenced by a preference to be addressed by their first name, to address the professional by title and last name and to see the professionals 'smartly' rather than 'casually' dressed). By contrast, participants appear to prefer a more symmetrical or familiar relationship with community psychiatric nurses, psychologists, occupational therapists and social workers (evidenced by their preference for mutual address on a first-name basis and the professional to be 'casually' rather than 'smartly' dressed), which may suggest different role expectations of familiarity versus authority. Indeed, for the care of long-term, severely mentally-ill people in the community, the principal coordinating mechanism for their care is the care

Table 3. Distribution of participants' preferences of forms of address and dress by GPs, psychiatrists, CPNs, psychologists, OTs, and social workers

\begin{tabular}{lccllll}
\hline Form of address & GP & Psychiatrist & CPN & Psychologist & OT & Social worker \\
\hline Self address: First name & $94(71 \%)^{*}$ & $91(68 \%)^{*}$ & $91(68 \%)^{*}$ & $95(71 \%)^{*}$ & $93(70 \%)^{*}$ & $94(71 \%)^{*}$ \\
Self address: Last name & $28(21 \%)^{*}$ & $31(23 \%)^{*}$ & $31(23 \%)^{*}$ & $27(20 \%)^{*}$ & $29(22 \%)^{*}$ & $28(21 \%)^{*}$ \\
Other address: First name & $14(11 \%)^{*}$ & $18(14 \%)^{*}$ & $87(65 \%)^{*}$ & $70(53 \%)^{*}$ & $83(62 \%)^{*}$ & $87(65 \%)^{*}$ \\
Other address: Last name & $109(81 \%)^{*}$ & $106(80 \%)^{*}$ & $35(26 \%)^{*}$ & $52(39 \%)^{*}$ & $39(29 \%)^{*}$ & $34(26 \%)^{*}$ \\
Dress: Smart/formal & $89(67 \%)^{*}$ & $88(66 \%)^{*}$ & $52(39 \%)$ & $65(49 \%)$ & $49(37 \%)$ & $47(35 \%)$ \\
Dress: Casual/informal & $29(22 \%)^{*}$ & $29(22 \%)^{*}$ & $65(49 \%)$ & $52(39 \%)$ & $68(51 \%)$ & $69(52 \%)$ \\
\hline
\end{tabular}

$\mathrm{GP}=$ general practitioner, $\mathrm{CPN}=$ community psychiatric nurse; $\mathrm{OT}=$ occupational therapist

* $P=0.02, \mathrm{df}=2$ (Chi-squared, Pearson) 
coordinator - one named person who is responsible to keep in close contact to ensure that agreed health and social care is given. Most keyworkers are social workers, community psychiatric nurses, occupational therapists and psychologists. Many severely mentally-ill people in the community are often relatively socially isolated and the care coordinator, who provides a reliable source of social contact over time, may come to be regarded in familiar terms, as a 'friend' rather than in simply professional terms. A study by Mangen and Griffith (1982), comparing patients allocated to a community psychiatric nurse or an out-patient psychiatrist, revealed that patients found nurses more approachable and sympathetic, particularly when they made house visits, and greater levels of satisfaction over time. McCabe et al (1999) similarly found that a good care coordinatorpatient relationship may improve the overall quality of life of long-term patients as the relationship becomes increasingly embedded in their overall appraisal of life.

While this survey might suggest personal preference differences of dress and address according to different professional roles, these preferences might also result from exposure to, and hence expectations of, different forms of dress and address by different professional groups. For instance, if people are typically referred to as 'clients' by social workers, they may associate the term with that professional group as opposed to others. Furthermore, because the present sample was drawn from patients involved in community mental health services, the results may be limited to this setting and may not necessarily extend to other clinical settings.

\section{Declaration of interest}

This survey is part of a 3-year project funded by the special trustees of St Bartholomew's Hospital, the Joint Research Board.

\section{References}

AMERICAN PSYCHIATRIC ASSOCIATION (1994) Diagnostic and Statistical Manual of Mental Disorders (4th edn) (DSM-IV). Washington, DC: APA.

Therapeutic relationships and quality of life: Association of two subjective constructs in schizophrenia patients. International Journal of Psychiatry, 45 $276-283$.

BENBASSAT, J., PILPEL, D. \& TIDHAR, M. (1998) Patients' preferences for participation in clinical decision making. Behavioural Medicine, 24, 81-89.

COOPER-PATRICK, L., GALLO, J. GONZALES, J. J., et al (1999) Race, gender, and partnership in the patientphysician relationship. Journal of the American Medical Association, 282. 583-589.

COULTER, A. (1999) Paternalism or partnership: Patients have grown up - and there's no going back. BMJ, 7212, 719-720.

GELLER, J. D., ASTRACHAN, B. M. \& FLYNN, H. (1976) The development and validation of a measure of the psychiatrist's authoritative domain. Journal of Nervous and Mental Disease, $162,410-422$

MANGEN, S. P \& GRIFFITH, J.H. (1982) Patient satisfaction with community psychiatric nursing: a prospective controlled study. Journal of Advanced Nursing, 7, 477-482.

MCGUIRE, R, MCCABE, R. \& PRIEBE, $S$. (2001) Theoretical frameworks for investigating and understanding the therapeutic relationship in psychiatry. Social Psychiatry and Psychiatric Epidemiology, 36, 557-564.

RITCHIE, C.W. HAYES, D. \& AMES, D. J. (2000) Patient or client? The opinions of people attending a psychiatric clinic. Psychiatric Bulletin, 24, 447-450.

SHEITON, S. B. (1998) The doctorpatient relationship. In Human Behaviour(ed. A. Studemire), pp. 3-35. Philadelphia: Lippincott-Raven

SWIFT, G., ZACHARIAH, M. \& CASY, P. R. (2000) A rose by any other name: psychiatric outpatients' views on dress and address. Irish Journal of Psychological Medicine, 17, 132-134.

WOOFF, K., GOLDBERG, D. P. \& FRYERS, T. (1988) The practice of community psychiatric nursing and mental health social work in Salford. Some implications for community care. British Journal of Psychiatry, 152, 783-792.

MCCABE, R., RÖDER-WANNER, U. U., HOFFMANN, K., et al (1999)

*Rebecca McGuire-Snieckus Unit for Social and Community Psychiatry, St Bartholomew's and the Royal School of Medicine, Queen Mary, University of London, William Harvey House, West Smithfield, London EC1A 7BE;

e-mail: r.a.mcguire@mds.qmul.ac.uk, Rosemarie McCabe Senior Research Fellow, Unit for Social and Community Psychiatry, Newham Centre for Mental Health, Stefan Priebe Unit for Social and Community Psychiatry, Newham Centre for Mental Health 